\title{
Research on 760mm Hot Tandem Mill Hydraulic AGC Control System
}

\author{
Kun Tong ${ }^{1, a}$, Ni Ke ${ }^{1, b}$, Mingzhe Che ${ }^{1}$ and Jinchun Song ${ }^{1, \mathrm{c}}$ \\ ${ }^{1}$ School of Mechanical Engineering, Northeastern University, Shenyang 110819, China \\ akobetong1120@163.com, bnike_neu@163.com, jchsong@mail.neu.edu.cn
}

Keywords: hydraulic AGC, fuzzy PID, simulation

\begin{abstract}
Through analyzing the 760mm hydraulic AGC production line of a Shandong factory, the characteristics, compositions and the mathematical model of hydraulic system of the hydraulic AGC are introduced. Based on those the system performance is analyzed on the working conditions by simulations through introducing the PID and fuzzy PID controller. The simulation analysis concluded that the system response time and overshoots with the fuzzy PID controller were better than before, which is in flavor of the production line commissioning and eventually running. The performance of AGC system affects the controlling accuracy of sheet thickness and yield of sheet directly. In order to accommodate the requirement of market and improve the competition of product, a steel plant from Shandong province entrusts relevant department to develop a set of hydraulic system, which is being debugged at present. Our paper mainly introduces the structure and feature of the system. With the mathematical model that accord with the working conditions being founded and PID and fuzzy PID based on the mathematical model being added, We have simulated the system using the software of MATLAB/SIMULINK, which supplies corresponding theoretical basis for the system's final operation ${ }^{[1]}$.
\end{abstract}

\section{The Introduction of the System}

The selected hydraulic system here is a special hydraulic system developed for a hot rolling 6-stand hydraulic AGC controlling system of a company from Shandong province referring to Fig1. The hydraulic system mainly consists of hydraulic power system, hydraulic servo valve control stand, hydraulic detecting and feedback system. The main pump of Hydraulic power system consists of three sets of electric-motor-driven constant-pressure axial variable piston pumps, two of which are used with the third one prepared. The main pump supplies corresponding hydraulic impetus assurance for all kind of hydraulic-controlling function tests, through manual regulation to achieve the needs of working conditions of different pressures and different flow. We selected a set of electronic-motor-driven gear pump group as the Assistant hydraulic pump of the system, with the attempt to realize constant back pressure of the hydraulic system. The hydraulic system realizes both the detection of the parameters which is the displacement of AGC down cylinder and working pressure and so on, and signal feedback. We listed the original parameters of the system according to the technical requirements of the equipment, referring Table 1. We selected the components of the system according to the original parameters. 
The selection of hydraulic motor. The hydraulic power unit consists of three same sets of hydraulic motor group. Considering that the flow (q) of each set of hydraulic motor group is $105 \mathrm{~L} / \mathrm{min}$, selecting four-pole motor with synchronous speed (n) being $1450 \mathrm{rpm}$, then the output volume of the hydraulic motor is:

$$
V_{\mathrm{P}}=q / n=100 \times 10^{3} / 1450=68.97(\mathrm{ml} / \mathrm{r})
$$

We selected three sets of Peking Huade constant-pressure axial variable piston pumps A10VSO71DR/31RPPA12N00( $V=71 \mathrm{ml} / \mathrm{r}$, rated working pressure is $28 \mathrm{MPa}$, peak pressure is $35 \mathrm{Mpa}$ )as the main pump of our hydraulic system. We selected a set of domestic high quality gear motor CBF-E50P $(V=50 \mathrm{ml} / \mathrm{r}$, rated working pressure is $16 \mathrm{Mpa}$, peak pressure is $20 \mathrm{Mpa})$ as the assistant motor of our system.

Table 1 System original parameters

\begin{tabular}{cccccc}
\hline $\begin{array}{c}\text { Maximum } \\
\text { rolling force }\end{array}$ & $\begin{array}{c}\text { Maximum displacement } \\
\text { of cylinder }\end{array}$ & bandwidth & Precision & $\begin{array}{c}\text { Movable } \\
\text { mass }\end{array}$ & $\begin{array}{c}\text { The adjusting } \\
\text { speed of roll gap }\end{array}$ \\
\hline $400(\mathrm{~T})$ & $120(\mathrm{~mm})$ & $15(\mathrm{~Hz})$ & $1 \%$ & $8(\mathrm{~T})$ & $5(\mathrm{~mm} / \mathrm{s})$ \\
\hline
\end{tabular}
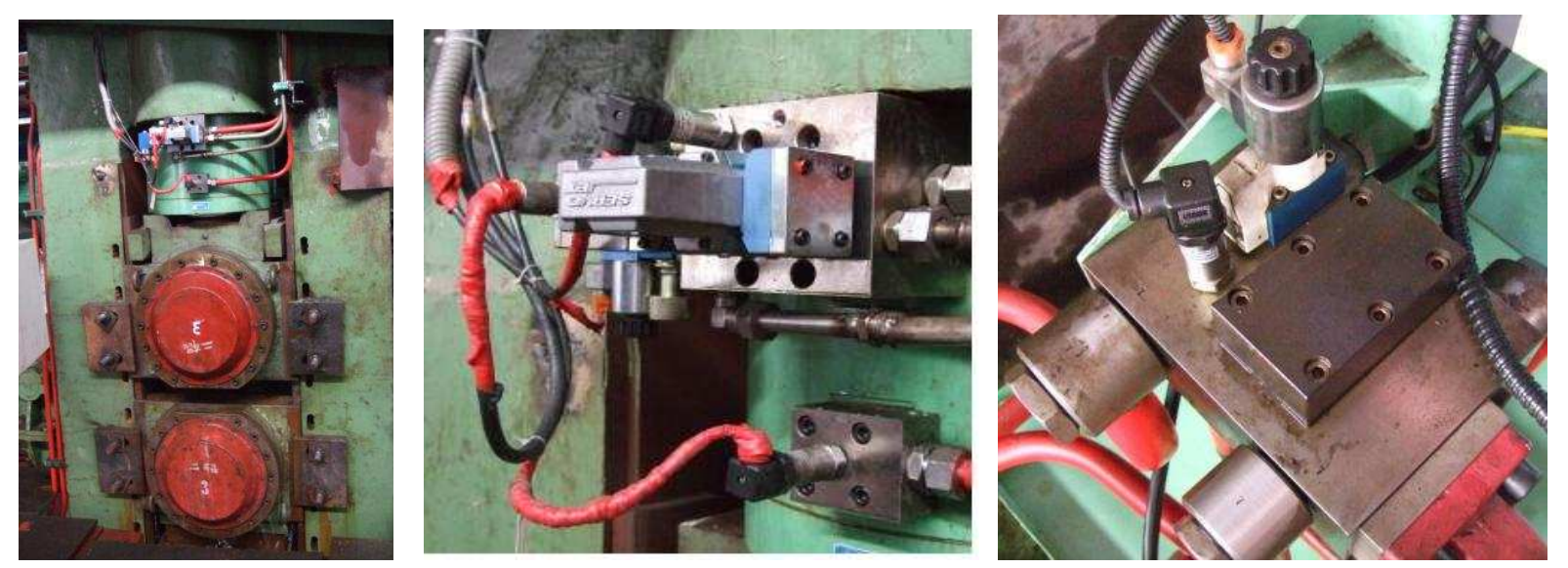

Fig. 1. Hot-rolled six frame Fig. 2. MOOG servo valve Fig. 3. Figure of pressure transmitter

The selection of servo valve. The servo controlling system is consisted on 6 body frames and 12 servo valves, with the designing of a oil cylinder controlled by one electric-hydraulic servo valve. The selected servo valve is the product of company MOOG imported from America with original packing referring with Fig 2. The servo valves on each body frame are equipped in a centralizedcontrol valve stand with other components. An electronic terminal block box and a lifting tool that can move the valve stand easily are equipped too ${ }^{[2,3]}$. Pipeline link ports and pressure detection ports of corresponding pressure transducer is set up on the valves to realize the needed controlling function.

The selection of displacement transducer and pressure transducer. A transducer is a kind of device or equipment that converts the detected non-electronic quantities into electronic quantities that have a certain relationship with the non-electronic quantities. It is an important detecting means in auto-control system. 
Transducers can be classified into strain gauge transducer, piezoelectric transducer, capacitive transducer, inductance type transducer, eddy current transducer and so on according to the working principle. Transducer should be selected according to the system accuracy which means that the accuracy of transducer should be higher by at least one order of magnitude than the accuracy of system. The bandwidth of displacement transducer should be at least $5 \sim 10$ times wider than the system's bandwidth. Otherwise the instantaneous true value of regulated variable cannot be detected. Meanwhile that will lead to a too high system's degree. Since rolling mill requires high accuracy of products (commonly in the order $\mu \mathrm{m}$ ), then the required accuracy of position control of down hydraulic cylinder is very high too.

The RH serial displacement transducer made by American MTS company is a kind of magnetostrictive displacement transducer, which can be applied in the hard working condition of high temperature, high pressure, hard oscillation and so on. The transducer's main using area is the constant position detecting and feedback of servo hydraulic cylinder in the smelting and steel rolling system. We selected diffused silicon pressure transmitter series P20S, referring to Fig 3.

The selection of electronic motor. When the system's peak working pressure $p$ is $27 \mathrm{MPa}$, we should adjust the working flow q of variable stroke pump to $90 \mathrm{~L} / \mathrm{min}, \eta$ efficiency is 0.8 , and then the needed maximum driven power of the pump is:

$$
P=p q / \eta=27 \times 10^{6} \times 90 \times 10^{-3} /(60 \times 0.8)=50.06(\mathrm{~kW})
$$

We selected 4-pole motor with synchronous speed $1480 \mathrm{rpm}$. The pump's maximum driven power is $55 \mathrm{~kW}$. The driven motor's power of each main pump of the hydraulic system is $55 \mathrm{~kW}$. The two set of motor pump group are working pump. The total power is $110 \mathrm{~kW}$. There is another set of standby motor group $(55 \mathrm{~kW})$. The power of the assistant pump motor of the hydraulic system is $5.5 \mathrm{~kW}$. Namely we selected motor: Y250M-4B35 (55KW). The synchronous speed is $1480 \mathrm{rpm}$, referring to Fig 4.

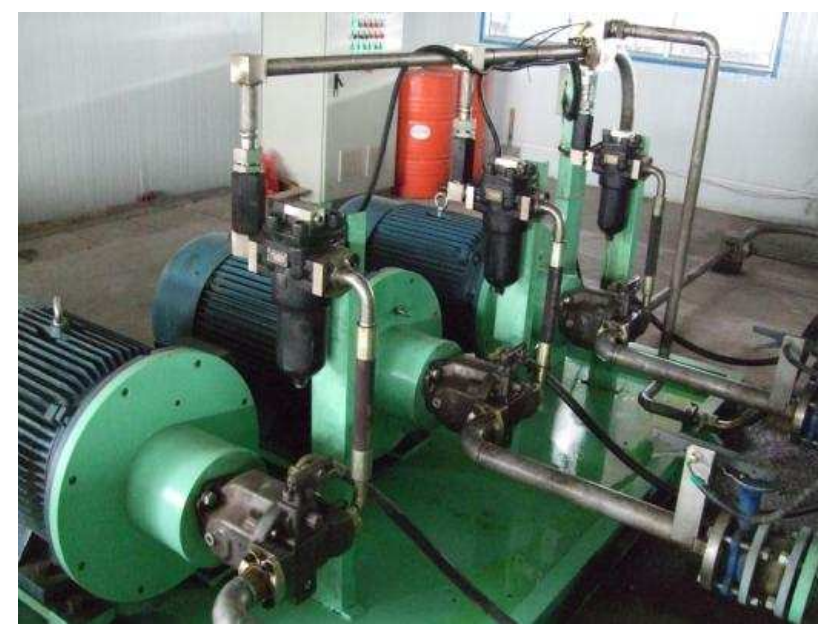

Fig. 4. Hydraulic station main motor

\section{The building of mathematical model of the hydraulic system}

Hydraulic AGC system is a kind of system that realizes roller's rolling gap through the control of rolling down hydraulic cylinder. It is the key system of modern strip miller, the function of which is to adjust rolling down cylinder's position automatically, regardless of the variation of all kinds of 
disturbance factors that bring thickness deviation. That will make the thickness of the exit strip constant which will guarantee the product quality. The disturbance factors that affect thickness are a lot and with complex variations. So the hydraulic AGC system consists of position inner loop and rolling force outer loop ${ }^{[4]}$.

The main components constructing an integrate hydraulic AGC system are servo valve, hydraulic cylinder, transducer, controlling regulator. At last, we have built the transfer function of each dynamic element separately and then deduce the mathematical model of the entire system.

The mathematical model of servo valve. In most hydraulic servo systems, the dynamic response of servo valve is always higher than that of actuator. So the transfer function of servo valve can be simplified $^{[5]}$. When the nature frequency of hydraulic actuator of hydraulic cylinder is higher than $50 \mathrm{~Hz}$, we can express the transfer function using two-order oscillate element, namely:

$$
W_{v}(s)=\frac{Q(s)}{I(s)}=\frac{K_{v}}{\frac{s^{2}}{\omega_{v}^{2}}+\frac{2 \xi_{v} s}{\omega_{v}}+1}
$$

In the formula, $K_{v}$ represents the hydraulic servo valve's flow gain, $\left(\mathrm{m}^{3} / \mathrm{s}\right) / \mathrm{A} . \omega_{v}$ is the nature frequency of hydraulic servo valve, rad/s. s represents Laplacian operator. $\xi_{v}$ represents the damping ratio of servo valve. We can get the nature frequency $\omega_{v}$ of servo valve from the frequency response curve made by the valve-making factory.

The mathematical model of servo hydraulic cylinder. Supposing: the joining pipe between the valve and hydraulic cylinder is short and wide, which is disposed in a symmetrical way. The pressure loss and pipe dynamic in the pipe can be ignored. The pressure of all the working cavity of the hydraulic cylinder is the same. Oil temperature and volume elasticity modulus is constant. Inner and outer leakage of hydraulic cylinder is laminar flow. We can give the flow continuity equation as follows ${ }^{[6]}$ :

$$
q_{\mathrm{L}}=A \frac{d y}{d t}+C_{\mathrm{i}}\left(P_{\mathrm{c}}-P_{\mathrm{b}}\right)+\frac{V_{0}}{\beta_{\mathrm{e}}} \times \frac{d P_{\mathrm{c}}}{d t}
$$

In the equation: $V_{0}$ represents the volume of control cavity, $\mathrm{m}^{3} q_{\mathrm{L}}$ represents the total volume that flow into the control cavity, $\mathrm{m}^{3} / \mathrm{s} . C_{\mathrm{i}}$ represents the inner leaking coefficient, $\left(\mathrm{m}^{3} / \mathrm{s}\right) / \mathrm{Pa} . P_{\mathrm{b}}$ represents the back pressure cavity oil pressure of hydraulic cylinder (constant), $\mathrm{N} / \mathrm{m}^{2} . P_{\mathrm{c}}$ represents the control oil cavity pressure of hydraulic cylinder, $\mathrm{N} / \mathrm{m}^{2} . \beta_{\mathrm{e}}$ represents hydraulic volume modulus of elasticity, $\mathrm{N} / \mathrm{m}^{2}$. $A$ represents the area of piston. $y$ represents the displacement of piston, $\mathrm{m}$.

We can deduce the transfer function between the displacement of the piston and the displacement of valve based on the above formula and literature as follows:

$$
Y=\frac{\frac{K_{\mathrm{q}}}{A}}{\omega_{2}\left(\frac{s}{\omega_{\mathrm{r}}}+1\right)\left(\frac{s^{2}}{\omega_{0}^{2}}+\frac{2 \xi_{0} s}{\omega_{0}}+1\right)} X_{v}
$$


In the formula, $\mathrm{Kq}$ represents flow gain, $\mathrm{m}^{2} / \mathrm{s} . \omega_{2}$ represents load stiffness to damping coefficient, $\mathrm{rad} / \mathrm{s}$. $\omega_{0}$ represents the nature frequency of the system that is composed of hydraulic spring mass coefficient and load spring mass coefficient, rad/s. $\xi_{0}$ represents damping ratio.

\section{The simulation of the system}

The simulation work is done using MATLAB/SIMULINK software based on the above mathematical model. The needed parameters refer to table 2 as follows;

Table 2 System parameters

\begin{tabular}{ccc}
\hline item & symbol & data \\
\hline the effective area of the cylinder cavity without rod & $A$ & $0.1256 \mathrm{~m}^{2}$ \\
the initial volume of the cylinder & $V_{0}$ & $0.0151 \mathrm{~m}^{3}$ \\
Hydraulic cylinder travel & $s$ & $0.12 \mathrm{~m}$ \\
Bulk elastic modulus of hydraulic & $\beta_{\mathrm{e}}$ & $7 \times 10^{8} \mathrm{Kg} / \mathrm{m}^{3}$ \\
Load elastic rigidity & $K$ & $7 \times 10^{8} \mathrm{Kg} / \mathrm{m}^{3}$ \\
Servo valve flow gain & $K_{v}$ & $0.0655\left(\mathrm{~m}^{3} / \mathrm{s}\right) / \mathrm{A}$ \\
Servo valve damping ratio & $\xi_{v}$ & 0.7 \\
Servo valve nature frequency & $\omega_{v}$ & $571.2 \mathrm{rad} / \mathrm{s}$ \\
Synthesis resonant frequency & $\omega_{0}$ & $308 \mathrm{rad} / \mathrm{s}$ \\
Synthesis damping ratio & $\xi_{0}$ & 0.4 \\
Hydraulic elastic rigidity & $K_{\mathrm{h}}$ & $7.313 \times 10^{8} \mathrm{~N} / \mathrm{m}$ \\
Load rigidity to damping coefficient & $\omega_{2}$ & $0.0081 \mathrm{rad} / \mathrm{s}$ \\
\hline
\end{tabular}

System simulation without controller. The simulation is done by inputting the above parameter into the model, during which we get the step response referring to Fig 5. From the picture, we can tell that the system's rise time is $0.135 \mathrm{~s}$, the overshooting number is 0 , adjustment time is $0.248 \mathrm{~s}$. The system's performance can be corrected farther more.

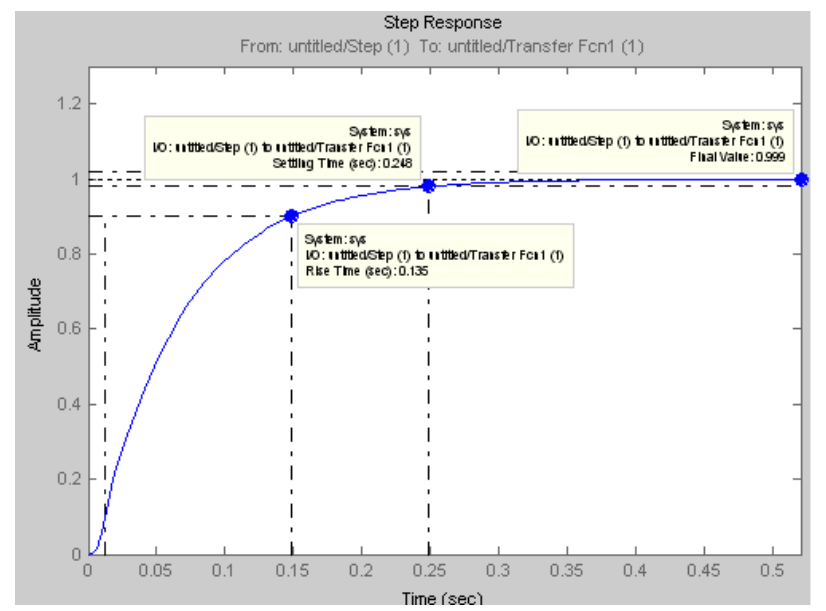

Fig. 5. System step-response

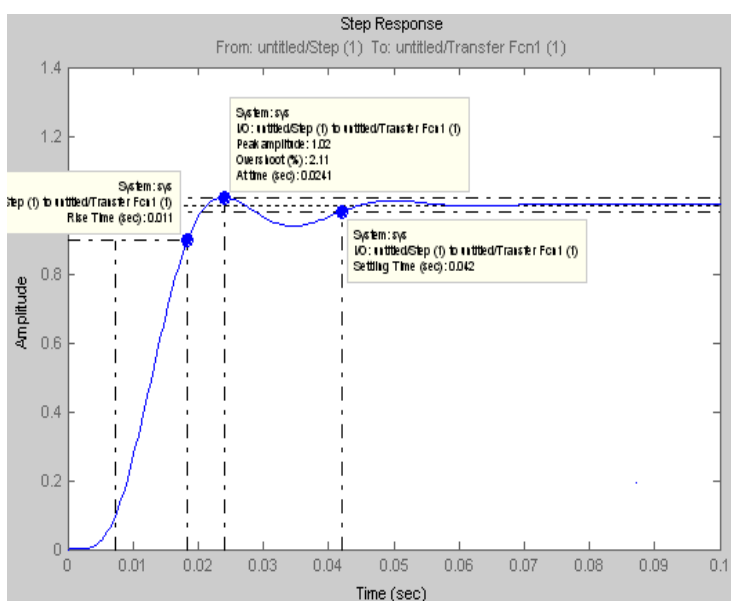

Fig. 6. System step-response with PID controller

PID correction. PID controller is a kind of linear controller, which can get the controlled quantity through linear combination of the proportion and integration and differentiation of the deviation e(t) between set value $r(t)$ and actual output value $c(t)$. The controlled quantity controls the controlled objects, because of which we call it PID control ${ }^{[7]}$.

$$
e(t)=r(t)-c(t)
$$


The control law is :

$$
G(s)=\frac{U(s)}{E(s)}=K_{\mathrm{p}}\left(1+\frac{1}{T_{\mathrm{i} S}}+T_{\mathrm{d} S}\right)
$$

In the formula, $K_{\mathrm{p}}$ represents proportional coefficient; $T_{\mathrm{i}}$ represents integral time constant; $T_{\mathrm{d}}$ represents differentiable time constant ${ }^{[7]}$. The PID controlling parameters is adjusted by the tryand error methods. The basic step of the adjustment is "first proportion, then differentiation, last integration". And finally we get the exact parameters: $K_{\mathrm{P}}=5, \quad K_{\mathrm{P}}=K_{\mathrm{P}} / T_{\mathrm{i}}=0.7, \quad K_{\mathrm{D}}=K_{\mathrm{P}} T_{\mathrm{D}}=0$. The simulation is done by inputting the above parameter into the model. The system's step response refers to Fig 6. From the picture we can tell the system's rise time is $0.011 \mathrm{~s}$, the overshooting number is $2.11 \%$, adjustment time is $0.042 \mathrm{~s}<0.1 \mathrm{~s}$. Comparably, the performance of the system that add PID controller is better than the performance of the system without PID controller.

Fuzzy PID controller. Fuzzy PID controller is the core of fuzzy control system. The performance of a fuzzy control system mainly depends on the structure, the adopted fuzzy law, compositional rule of inference, fuzzy decision-making methods of the system and other related factors ${ }^{[8]}$. So in a fuzzy controlling system, the designation and adjustment of fuzzy controller is very important.

From the system's response picture, we can tell: the rise time of system is $0.0136 \mathrm{~s}$, overshooting number is $1.05 \%<2.11 \%$, adjustment time is $0.0395 \mathrm{~s}<0.042 \mathrm{~s}<0.1 \mathrm{~s}$, the performance of the system is better in some degree.

\section{Conclusion}

(1) The results of the simulation have proved the correctness of the component selection

(2) The performance of the system becomes better by adding PID and fuzzy PID controller. The rise time is $0.011 \mathrm{~s}$ from $0.135 \mathrm{~s}$; adjustment time is $0.1 \mathrm{~s}$ from $0.1 \mathrm{~s}$ through $0.042 \mathrm{~s}$.

(3) Some more intelligent controller ${ }^{[9]}$ are not concerned, such as adaptive PID, symposium adaptive controller and so on.

\section{References}

[1] Wang You-long. Analysis and discussion on Mill AGC system servo valves faults [J]. Machine Tool \& Hydraulic, 2010,38(4): 101-103.

[2] Dr Marko Mailand. A multi-channel, high-precision sensor interface for low-power applications[J]. IEEE Trans Elec Dev, 2003, 45(12): 10-16.

[3] Chaisson, Keman. The US air force plans to field a new generation of unmanned airborne sensor platform[J]. Journal of Electronic Defense, 2002, 3(8): 69-76.

[4] Remn-Min Guo. Evaluation of Dynam ic Characteristics of HAGC System[J]. Iron and steel Engineer, 1991,68(7): 52-62

[5]Armao F G. Design and fabrication of aluminum automobiles [J].Welding Innovation, 2002, 19(2): 2-6.

[6] HE S, SEPEHRI N. Modeling and prediction of hydraulic servo actuators with neural networks[C]. Proceedings of the American Control Conference, 1999(3): 708-712.

[7] Chen Tan Wen. Robust Controller Design and PID Turning for Multivariable Processes[J]. Asian Journal of Control, 2002(4): 439-451.

[8] K.J.Astrom, T.Hagglond. Automatic Tuning of PID Controllers [J]. Instrument Society of America, 1998, 62(6): 27-31.

[9] C.B Lee, H.W Wu. Self-tuning Adaptive Speed Control for Hydraulic Transmission systems [J].Int. J of 